\title{
Urgences
}

\section{Rocaille d'octobre}

\section{Carole Rondeau}

Numéro 16, mars 1987

D.G. Jones : d'un texte, d'autres

URI : https://id.erudit.org/iderudit/025404ar

DOI : https://doi.org/10.7202/025404ar

Aller au sommaire du numéro

Éditeur(s)

Urgences

ISSN

0226-9554 (imprimé)

1927-3924 (numérique)

Découvrir la revue

Citer ce document

Rondeau, C. (1987). Rocaille d'octobre. Urgences, (16), 82-83.

https://doi.org/10.7202/025404ar d'utilisation que vous pouvez consulter en ligne.

https://apropos.erudit.org/fr/usagers/politique-dutilisation/ 


\section{Carole Rondeau ROCAILLE D'OCTOBRE}

Jardin d'ombres en ruine sous la pluie tombante, tombeau de fleurs

amassant les couleurs

des feuilles mortes. Pourtant

les pierres fleurissent

comme dans les tomes d'un recueil les paroles de ceux qui ne sont plus se font encore entendre.

De plus en plus ma bouche s'emplit de roches et les os de mes collègues

poussent comme des fleurs.

Quelle jonglerie que ceci, paradis éternel, monument aux rois défunts

ou centre-ville universellement désert, le soir, passé $10 \mathrm{~h}$ ? Il n'a rien d'humain, ce jardin

de morts vivants. Je le longe, sombre sous la pluie qui tombe. Il est jonché de runes. 


\section{Difficultés}

Celles-là même prédites par D.G. Jones: jeux de mots, jeux de sonorités - le tout intraduisible, à moins de s'en tenir à la lettre... ou d'oser ce que je n'ose pas.

\section{Contrainte et liberté}

Plus de l'une que de l'autre, car j'aime trop l'image de l'université en péril - cette «inner city» déserte, ce quasi-cimetière menacé de ruine, ce monument de pierres sculptées à l'effigie d'anciens rois et gravées d'inscriptions runiques...

\section{Refiguration}

Pourquoi faire? Pour représenter sous une forme encore plus «visible» le «jardin» en question?

\section{Autonomie du texte cible}

«A moot question..."

\section{Poésie de D.G. Jones}

Il pleure en épluchant des oignons, la vue d'une paire de gants mauves suffit à l'émouvoir...

J'aime encore mieux me contenter de le lire, que de chercher à le traduire. 